\title{
Manipulating prohibitin levels provides evidence for an in vivo role in androgen regulation of prostate tumours
}

\author{
D Alwyn Dart, Bradley Spencer-Dene ${ }^{1}$, Simon C Gamble, Jonathan Waxman \\ and Charlotte L Bevan
}

\begin{abstract}
Androgen Signalling Laboratory, Department of Oncology, Imperial College London, Du Cane Road, London W12 0NN, UK ${ }^{1}$ Department of Histopathology, Imperial College London and Experimental Pathology Laboratory, Cancer Research UK, Lincoln's Inn Fields, London WC2A 3PX, UK
\end{abstract}

(Correspondence should be addressed to C L Bevan; Email: charlotte.bevan @imperial.ac.uk)

\begin{abstract}
Current hormonal therapies for prostate cancer are effective initially, but inevitably tumours progress to an advanced, metastatic stage, often referred to as 'androgen independent'. However, the androgen receptor (AR) signalling pathway is still key for their growth. It is speculated that tumours escape hormonal control via reduction in corepressor proteins. Manipulating such proteins is thus a potential therapeutic strategy to halt or even reverse tumour progression. We aimed to elucidate the effects of altering levels of the AR corepressor and androgen-target protein prohibitin (PHB) on prostate tumour growth. Prostate cancer cells incorporating an integrated androgen-responsive reporter gene and stably expressing vectors to inducibly overexpress or knockdown PHB were generated and used to assess effects on androgen signalling (by real time imaging) and tumour growth both in culture and in vivo. PHB overexpression inhibited AR activity and prostate-specific antigen (PSA) expression as well as androgen-dependent growth of cells, inducing rapid accumulation in $\mathrm{G}_{0} / \mathrm{G}_{1}$. Conversely, reduction in PHB increased AR activity, PSA expression, androgen-mediated growth and S-phase entry. In vivo, doxycycline-induced PHB regulation resulted in marked changes in AR activity, and showed significant effects upon tumour growth. Overexpression led to tumour growth arrest and protection from hormonal starvation, whereas RNAi knockdown resulted in accelerated tumour growth, even in castrated mice. This study provides proof of principle that i) reduction in PHB promotes both androgen-dependent and 'androgen-independent' tumour growth, and ii) altering AR activity via increasing levels or activity of corepressors is a valid therapeutic strategy for advanced prostate cancer.
\end{abstract}

Endocrine-Related Cancer (2009) 16 1157-1169

\section{Introduction}

Prostate cancer is the most commonly diagnosed cancer in males, accounting for $25 \%$ of new cases in both the United States and Europe, where it is the second and third leading cause of male cancer deaths respectively (Ferlay et al. 2007, Jemal et al. 2008). The androgen signalling pathway is central in prostate cancer progression and therapy, as tumours are initially dependent upon androgens for growth (Agoulnik \& Weigel 2006). The principal circulating androgen is testosterone, produced by the testis, while weaker androgens and precursors are also produced by the adrenal glands (Kokontis \& Liao 1999). Prostate development is driven by the potent androgen dihydrotestosterone (DHT), produced within prostate cells by the action of $5 \alpha$-reductase enzymes on testosterone. Cellular responses to androgens are mediated by the androgen receptor (AR), a ligand-activated transcription factor and member of the nuclear receptor superfamily (Gelmann 2002). In the absence of ligand, AR is cytoplasmic; ligand binding induces an active conformation and translocation into the nucleus where it binds specific androgen response elements 
(AREs) in the regulatory regions of target genes, thus influencing rates of gene transactivation. AR then recruits regulatory protein complexes to the promoters of these genes (Tsai \& O'Malley 1994).

Response elements for the AR and the closely related glucocorticoid receptor (GR), progesterone receptor and mineralocorticoid receptor are hexameric bipartite binding sites, with the consensus sequence consisting of an inverted repeat of TGTTCT with a three nucleotide spacer (Beato et al. 1989). The AR can bind to these canonical elements, but promoter analysis of androgen-responsive genes revealed additional nonconsensus response elements with apparent AR specificity. Two well-studied examples are the rat dorsal prostate-specific probasin $(P B)$ promoter and the prostate trans-epithelial transporter of IgM (secretory component or SC) promoter (Dodd et al. 1983, Rennie et al. 1993, Mostov 1994, Claessens et al. 1996, Verrijdt et al. 1999). Within these, specific AREs differ from the classical inverted TGTTCT, having a greater similarity to a direct repeat of the same sequence, but with a change of $T-G$ in the first base that increases AR while decreasing GR binding (Claessens et al. 1996, Schoenmakers et al. 1999, 2000).

Therapies for advanced prostate cancer usually involve anti-androgens. Although initially successful, such therapies inevitably fail and patients relapse with 'androgen-independent tumours'. However, the AR is still required for tumour growth, and in many cases, tumours circumvent the requirement for high levels of androgens by receptor amplification, or mutation resulting in a receptor with broadened ligand responsiveness (Brinkmann \& Trapman 2000, Gelmann 2002, Isaacs \& Isaacs 2004, Agoulnik \& Weigel 2006). The exact mechanisms of anti-androgen action are poorly understood, but they appear to promote the recruitment of repressive protein complexes, or corepressors, to the AR (Wang et al. 2005, Powell et al. 2006). Which corepressors may be required for in vivo repression of the AR by antiandrogens is not known, but potentially these will be candidates involved in disease progression and in development of 'androgen-independent' growth. One such potential AR corepressor is prohibitin (PHB). PHB is a highly conserved $32 \mathrm{kDa}$ protein with dual roles within the cell (McClung et al. 1995, Coates et al. 1997). Within mitochondria, PHB is located in the inner membrane where it functions as a chaperone/ holdase complex for newly imported proteins (Nijtmans et al. 2002). However, PHB has been found in the nucleus of several steroid hormoneresponsive cell lines where its functions are more complex. PHB is reported to have tumour suppressor, anti-proliferative and cell cycle regulation activities, largely accomplished through its repression of E2F activity. E2F transcription factors regulate genes involved in differentiation, proliferation and apoptosis; and, together with the retinoblastoma $(\mathrm{pRb})$ protein, they regulate the $G_{1} / S$ transition. PHB appears to repress E2F via recruitment of HDAC1, NCoR and BRG1/Brm (Choi et al. 2008), thus condensing chromatin and silencing gene activation. Overexpression of PHB results in $\mathrm{G}_{1} / \mathrm{S}$ arrest and the inhibition of E2F-mediated apoptosis (Fusaro et al. 2002).

We previously showed that PHB represses liganddependent AR activity and also inhibits androgenstimulated growth of prostate cancer cells, in vitro (Gamble et al. 2007). Furthermore, we found PHB protein levels in prostate cancer cells to be downregulated in response to androgens (Gamble et al. 2004), presumably enabling androgen-stimulated cell cycle entry and growth. More recently, PHB has been shown to be a corepressor of the oestrogen receptor (ER $\alpha$; He et al. 2008), associating with oestrogenregulated promoters in the absence of hormone and dissociating after hormone treatment. Interestingly, PHB has been implicated in mediating the antiproliferative actions of anti-oestrogens, and reduction in PHB levels reduced the anti-proliferative actions of such ER antagonists (Wang et al. 2004). These studies, together with the report that PHB is required for the recruitment of the BRG1-containing chromatin remodelling complex to antagonist-bound AR (Dai et al. 2008), make PHB an excellent candidate AR corepressor, important in prostate cancer progression and therapy. We tested this hypothesis by investigating the effects of manipulating PHB levels in human prostate cancer cells on AR activity and tumour cell growth, in culture and in vivo, in response to hormone treatment.

\section{Materials and methods}

\section{Cell culture}

All cells were maintained at $37{ }^{\circ} \mathrm{C}, 5 \% \mathrm{CO}_{2}$, in media containing $2 \mathrm{mM}$ L-glutamine, 100 units $/ \mathrm{ml}$ penicillin and $100 \mathrm{mg} / \mathrm{ml}$ streptomycin (Sigma). LNCaP/TR2 cells were maintained in RPMI medium (Sigma) supplemented with $10 \%$ tetracycline-free foetal bovine serum (Clontech) and $12 \mu \mathrm{g} / \mathrm{ml}$ blasticidin (Invitrogen), and $\mathrm{LNCaP} / \mathrm{Luc}$ with the further addition of G418 $(500 \mu \mathrm{g} / \mathrm{ml})$. Where cells were further stably transfected with PHB overexpression or knockdown plasmids, $0.3 \mathrm{mg} / \mathrm{ml}$ zeocin (Invitrogen) was added. COS-1 cells were maintained in DMEM medium 
(Sigma) supplemented with $10 \%$ foetal bovine serum (First Link UK, Ltd, Brierley Hill, UK). Twenty-four hours before exposure to androgen, medium was replaced with 'starvation medium' consisting of phenol red-free RPMI or DMEM medium as appropriate supplemented with 5\% charcoal-stripped foetal bovine serum (First Link UK).

\section{Reporter construction}

A $168 \mathrm{bp}$ fragment containing the minimal thymidine kinase $(t k)$ promoter from the herpes simplex virus was cloned into the Sac1/Xho1 site of pGL4 (Promega) to generate $\mathrm{p}$ - $t k$-Luc. DNA oligomers (EurofinsMWG, Ebersberg, Germany) coding for the SC1.2 ARE sequence were ligated into the Sac1/Xbal site of $\mathrm{p}$ - $t$-Luc to generate p-t $k$-Luc-ARE (Fig. 1A). The $3 \mathrm{~kb}$ fragment of the chicken lysozyme $5^{\prime}$-matrix attachment region (MAR) was provided by Georges Vassaux (CRUK, London, UK). Blunted MAR fragments were ligated into the Sma1 and BamH1 sites (restriction mapping confirmed directionality) of p-tk-Luc-ARE to create pARE.MAR.

\section{Generating a tetracycline-inducible system}

LNCaP/TR2 cells expressing the Tet repressor were generated as described (Gamble et al. 2007) and stably transfected with the following vectors. PHB cDNA was cloned into pcDNA4/TO (Invitrogen). For siRNA knock down, a H1 promoter for RNA pol III (containing two Tet-repressor binding sites) was cloned into a promoter-less pcDNA3 vector (Invitrogen), generating pcDNA/ $2 \times$ TetR plasmid, then 65 mer oligos for hairpin siRNA against PHB, based on previously validated RNA duplexes (Gamble et al. 2004), were inserted downstream.

\section{Transient transfection}

COS-1 cells grown in 24-well plates were transfected using Fugene 6 (Roche Products Ltd) with $1 \mu \mathrm{g}$ androgen-responsive luciferase reporter, $50 \mathrm{ng}$ AR expression vector (pSVAR) and $100 \mathrm{ng}$ $\beta$-galactosidase control vector (PDM-LAC-Z- $\beta$-GAL) per well.

A
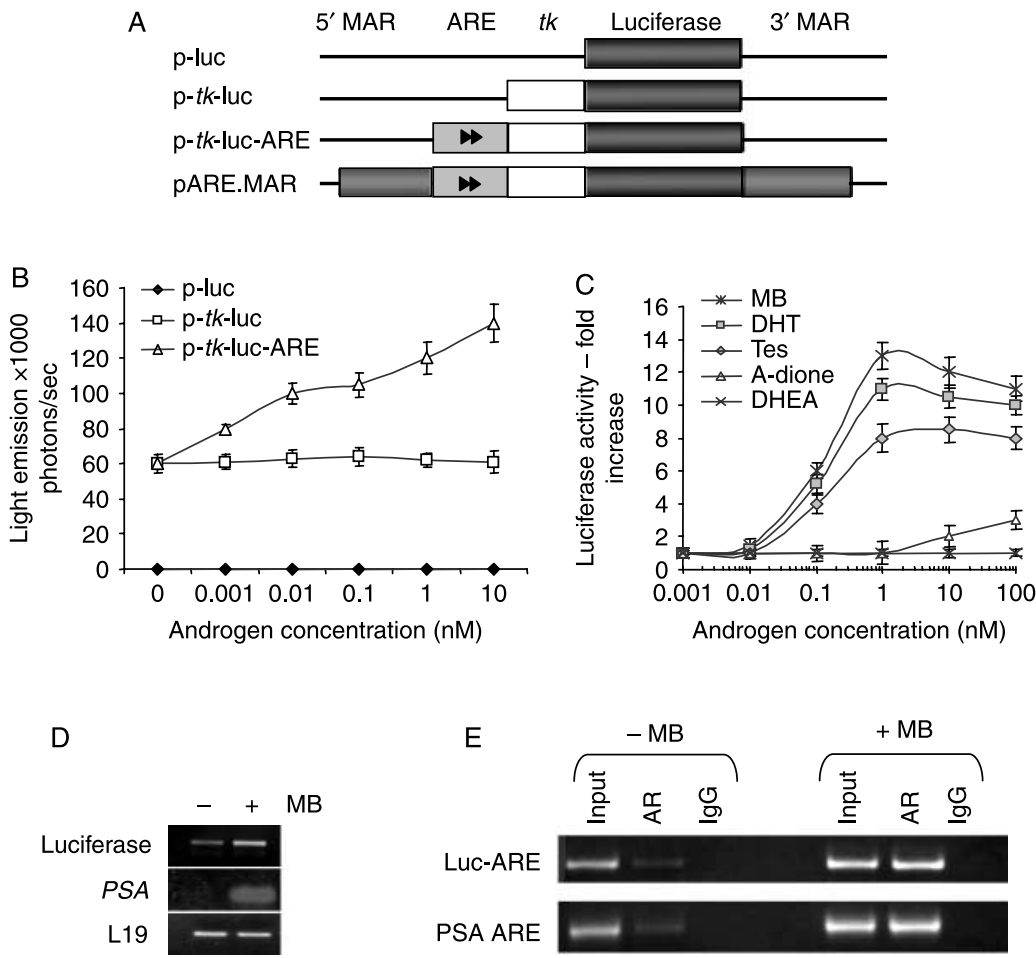

Figure 1 Construction and testing of androgen-responsive reporter vectors. (A) Sequential construction of vectors. (B) COS-1 cells were transfected with AR expression vector and luciferase construct as indicated, and then treated with $0.001-10 \mathrm{nM} M B$ for $24 \mathrm{~h}$. Results are mean \pm S.E.M. of three experiments. (C) LNCaP/Luc cells were treated with androgens (0-100 nM) for $24 \mathrm{~h}$. Luciferase activity was assayed and normalized by SRB assay. (D) Increase of luciferase and PSA mRNA transcripts in LNCaP/Luc cells after $6 \mathrm{~h}$ treatment with MB. (E) ChIP analysis of the PSA gene promoter and the integrated luciferase reporter promoter in LNCaP/Luc cells after $2 \mathrm{~h} \mathrm{MB}$ treatment (10 nM). MB, mibolerone; DHT, dihydrotestosterone; Tes, testosterone; A-dione, androstenedione;

DHEA, dehydroepiandrosterone; PSA, prostate-specific antigen. 


\section{Luciferase assay}

Cells were washed in ice-cold PBS and lysed in reporter lysis buffer (Promega). Lysate was mixed with luciferin substrate (Perkin-Elmer, Warrington, Cheshire, UK) and light emission measured using the Steadylite luciferase assay kit (Perkin-Elmer) in a Topcount luminometer (Packard Instrument Co., Meriden, CT, USA). Transfections were normalized to $\beta$-galactosidase activity, measured using the Galacton Tropix chemiluminescent kit (Applied Biosystems, Warrington, UK).

\section{Generating stably transfected cell lines}

LNCaP/TR2 cells were transfected with linearized pARE.MAR using Fugene 6 (Roche). Cells were grown for $24 \mathrm{~h}$ before G418 $(500 \mu \mathrm{g} / \mathrm{ml})$ selection commenced. After 2-3 weeks, single colonies were expanded into cell lines and tested for luciferase expression by live-cell imaging, western blotting and semi-quantitative RT-PCR. The cell line was named LNCaP/Luc.

\section{RNA extraction and RT-PCR}

RT-PCR for prostate-specific antigen (PSA) and L19 control was carried out as described (Gamble et al. 2007). Luciferase was detected using the primer pairs $5^{\prime}$-gctcagcaaggaggtaggtg- $3^{\prime}$ and $5^{\prime}$-tcttaccggtgtccaagtcc- $3^{\prime}$ with $22-24$ cycles of $94{ }^{\circ} \mathrm{C}$ for $30 \mathrm{~s}, 54^{\circ} \mathrm{C}$ for $30 \mathrm{~s}$ and $70{ }^{\circ} \mathrm{C}$ for $1 \mathrm{~min}$. TaqMan PCR assays for each gene target were performed in triplicate on cDNA samples in 96-well optical plates on an ABI Prism 7700 Sequence Detection system (PE Applied Biosystems). For each $20 \mu \mathrm{l}$ TaqMan reaction, $2 \mu \mathrm{l}$ cDNA was mixed with $7 \mu \mathrm{l} \mathrm{PCR}$-grade water, $10 \mu \mathrm{l} 2 \times$ TaqMan Universal PCR Master Mix (PE Applied Biosystems) and $1 \mu \mathrm{l}$ Taqman assay probe. PCR parameters were $50{ }^{\circ} \mathrm{C}$ for $2 \mathrm{~min}, 95^{\circ} \mathrm{C}$ for $10 \mathrm{~min}, 40$ cycles of $95^{\circ} \mathrm{C}$ for $15 \mathrm{~s}$ and $60{ }^{\circ} \mathrm{C}$ for $1 \mathrm{~min}$. Data were recorded using Sequence Detector Software (SDS version 2.3; PE Applied Biosystems). From each amplification plot, a threshold cycle $\left(C_{\mathrm{t}}\right)$ value was calculated, representing the PCR cycle number at which the fluorescence was detectable, based on the variability of base line data in the first 15 cycles. PSA levels were normalized to glyceraldehyde-3-phosphate dehydrogenase (GAPDH) levels.

\section{Immunoblotting}

Cell pellets were lysed in RIPA buffer. $20 \mu \mathrm{g}$ of extract was separated by SDS-PAGE and electroblotted onto nitrocellulose membranes. Non-specific binding was blocked in tris-buffered saline (TBS) with $0.05 \%$ Tween-20 and 5\% w/v non-fat dried milk. Primary antibodies were mouse monoclonals against $\beta$-actin
(Abcam, Cambridge, MA, USA @ 1:5000) or PHB (Thermo Fisher Scientific, Cheshire, UK @ 1:1000). Peroxidase-labelled rabbit anti-mouse secondary antibodies (Dako, Ely, UK) were used at 1:2000. The membrane was then incubated in chemiluminescent substrate (Amersham), and light emission detected by autoradiography.

\section{Chromatin immunoprecipitation}

Cells $\left(1 \times 10^{7}\right)$ were grown in starvation medium for 3 days, and then treated with hormone $(10 \mathrm{nM}$ mibolerone (MB)) for $2 \mathrm{~h}$. ChIP was performed on formaldehyde cross-linked cell samples essentially as described (Zhang et al. 2003). Primer sets for the PCR included PSA ARE (5'-tctgcctttgtccctagat- $3^{\prime}$ and $5^{\prime}$-aaccttcattcccaggact- $3^{\prime}$ ) and $S C 1.2$ ARE $\left(5^{\prime}\right.$-gccaagcttacttagatctcgagatctgcggcacgc- $3^{\prime}$ and $5^{\prime}$-ggagagctccggctctttcagttctgcggecgetct- $3^{\prime}$ ), both amplifying a $200 \mathrm{bp}$ fragment across the ARE. $5 \mu \mathrm{l}$ of DNA was used for the PCR with 30-35 cycles of $94{ }^{\circ} \mathrm{C}$ for $30 \mathrm{~s}, 57^{\circ} \mathrm{C}$ for $45 \mathrm{~s}$ and $70{ }^{\circ} \mathrm{C}$ for $45 \mathrm{~s}$.

\section{Cell cycle analysis}

Cells were grown in starvation medium for 48-72 $\mathrm{h} \pm$ doxycycline, and then treated with hormone for 24-48 h. Cells were then trypsinized, washed twice in PBS, fixed in $70 \%$ ethanol at $4{ }^{\circ} \mathrm{C}$, were stained with $5 \mathrm{mg} / \mathrm{ml}$ propidium iodide and RNA removed using $50 \mathrm{mg} / \mathrm{ml} \mathrm{RNase} \mathrm{A.} \mathrm{FACS} \mathrm{analysis} \mathrm{was} \mathrm{carried} \mathrm{out}$ using a FACS Calibur (Beckton-Dickinson, Oxford, UK), using linear scale representation of forward and side scatter during flow analysis, as well as DNA content. Single cells were gated and the cell cycle profiles measured. A total of 10000 events were measured per sample.

\section{Growth of xenografts}

Surgically castrated 8-week male BALB/c strain nude mice (Harlan, Bicester, UK) were injected subcutaneously with $0.5 \mathrm{ml} \mathrm{LNCaP/Luc} \mathrm{cells} \mathrm{suspended} \mathrm{in}$ Matrigel $\left(1 \times 10^{6}\right.$ cells $\left./ \mathrm{ml}\right)$. Daily injections of testosterone propionate $(50 \mu \mathrm{g}$ in $90 \%$ propylene glycol and $10 \%$ ethanol) were given until tumours were confirmed ( $\sim 2$ weeks after challenge). For PHB manipulation within the LNCaP/Luc cells, doxycycline was administered in drinking water $(20-200 \mu \mathrm{g} / \mathrm{ml})$. Tumours were measured daily using callipers and volumes calculated using the formula width ${ }^{2} \times$ length/2 (Janik et al. 1975). Tumours were allowed to grow to $15 \mathrm{~mm}$ diameter, when the animals were killed, tumours resected and fixed in neutral-buffered formalin. Statistical significance was calculated using the Mann-Whitney $U$ analysis. 
Animals received food and water ad libitum and were monitored for ill effects. All work was carried out in accordance with the provisions of the Animals (Scientific Procedures) Act 1986 of the United Kingdom (HMSO, London, UK, 1990) and with appropriate local ethical and Health and Safety approval.

\section{Luciferase imaging}

Cells were grown in 24-well plates, and D-luciferin substrate (Xenogen, $20 \mu \mathrm{l}$ per well) was added into the medium. Mice were injected i.p. with D-luciferin (Caliper Life Sciences Ltd, Runcorn, UK) at $150 \mathrm{mg} / \mathrm{kg}, 10 \mathrm{~min}$ before imaging. Anaesthetized mice (3\% isoflurane, Abbott Animal Health UK) were placed into a light-tight camera box. Light emission from luciferase was detected by the IVIS Imaging System 100 series (Xenogen Corporation), and overlaid as a pseudocolour image with reference scale, upon a greyscale optical image. Photon emission was later normalized either to cell number, measured using the sulphorhodamine B assay as previously described (Skehan et al. 1990), or to tumour volume.

\section{Measurement of serum doxycycline and testosterone}

Serum was collected from mice given doxycycline $(0-2 \mathrm{mg} / \mathrm{ml})$ in their drinking water for $24 \mathrm{~h}$. The pcDNA6/TR plasmid (Invitrogen) expressing the Tet repressor and pcDNA4/TO/Luc (expressing tetracycline-regulated luciferase cDNA) were transiently transfected (100 ng/well each) into COS-1 cells, grown on 96-well plates in tetracycline-free medium. This was replaced by medium containing increasing doxycycline $(0-100 \mu \mathrm{M})$ to generate a standard curve, against which the mouse serum samples were analysed. Total testosterone from mouse serum was measured using ELISA kits (Calbiotech, CA, USA).

\section{Histology and immunohistochemistry}

Standard protocols were carried out as described (Powell et al. 2004, 2006). Antibodies used were: mouse anti-human PHB primary antibody (AbCam Ltd @ 1:500); Ki67 (DAKO M7249 @ 1:50); phosphohistone H3 (Millipore UK Ltd, Watford, UK 06-570 @ 1:250). The Vectastain avidin-biotin complex (ABC from Vector Labs, Peterborough, UK) was used for detection, using diaminobenzidine chromogenic substrate. Negative controls lacking primary antibody were also carried out. Digital images were captured using E1000 microscope (Nikon, Kingston upon Thames,
UK) and Eclipse Net image analysis software. Ki67 and phospho-histone H3-positive cell were counted within five different areas within the tumour, containing $\sim 200$ cells each, for four to five tumours per group.

\section{Results}

\section{Generation and characterization of androgen-responsive reporter cell lines}

Our aim was to create a luciferase reporter construct responding specifically to androgen stimulation, with minimal crosstalk with other steroids. This was tested initially by cotransfection with AR expression vector into COS-1 cells. The backbone vector (p-luc in Fig. 1) produced no significant luciferase signal above autofluorescent background upon treatment with androgen, while activity of a positive control reporter vector (MMTV-luc, containing multiple response elements) was induced eight- to tenfold (data not shown). Addition of a minimal $t k$ promoter from the herpes simplex virus ( $\mathrm{p}$-t $k$-luc) increased luciferase signal output, producing a basal detectable level of luciferase activity, which was not hormone-inducible, or affected by the presence of steroid hormone receptors (Fig. 1B). The introduction of a single copy of a $S C 1.2$ ARE sequence (p-tk-luc-ARE) conferred hormone inducibility to this minimal promoter, resulting in two- to threefold induction (Fig. 1B). Other AREs were similarly tested; however, the $S C 1.2$ ARE was selected as it showed the greatest degree of hormone induction and specificity for AR, since it was not greatly activated by other transfected or endogenous steroid receptors in various cell lines (Supplementary Figures 1 and 2, which can be viewed online at http://erc.endocrinology-journals.org/supplemental/). Next, MAR were added upstream and downstream of the reporter cassette to generate the insulated pARE.MAR vector (Fig. 1A). This was transfected into LNCaP/TR2 cells (stably expressing the tetracycline repressor protein; Gamble et al. 2007). Clones were tested for androgen-inducible luciferase activity and for cross-reactivity or activation by other steroid hormones and their receptors. The clone selected, named LNCaP/Luc, demonstrated strong androgendependent induction of luciferase activity. The synthetic androgen MB was the most potent activator giving 14-fold induction of luciferase activity. The testicular-derived androgens testosterone and DHT gave eight- and tenfold induction of luciferase respectively, at their physiologically relevant levels of 1-10 nM (Fig. 1C). Since circulating adrenal androgens are contributory but variable agonists of 
the AR, these were also tested. In comparison with testosterone and DHT, the adrenal androgens were weak inducers with androstenedione (A-dione) weakly activating the reporter at $10-100 \mathrm{nM}$, concentrations higher than the physiologically relevant normal range $(\sim 1-5 \mathrm{nM})$. Dehydroepiandrosterone produced no measurable signal at this range.

On treatment with MB, luciferase RNA transcripts were detectable within $6 \mathrm{~h}$ (Fig. 1D) and enzymatic activity was detectable within $16 \mathrm{~h}$ (data not shown). Luciferase enzymatic activity was undetectable after $8 \mathrm{~h}$ of hormone starvation (data not shown). To investigate AR occupancy of the SC1.2 ARE, hormonally starved cells were treated with $\mathrm{MB}$ for $2 \mathrm{~h}$ and then harvested for ChIP analysis of a $200 \mathrm{bp}$ region of the constructed AR reporter, spanning the $\mathrm{ARE}$ and $t k$ promoter. As expected, AR was present on this ARE in the presence, but in not the absence, of hormone (Fig. 1E). Identical results were found at the regulatory region of the endogenous androgen-responsive gene, PSA.

\section{PHB influences AR activity and cell cycle distribution in vitro}

Previously, we showed that PHB overexpression from stably integrated tetracycline-inducible vectors could repress androgen-dependent endogenous gene expression and androgen-stimulated growth of $\mathrm{LNCaP}$ cells in vitro (Gamble et al. 2007). Therefore, the same doxycycline-inducible vector (pcDNA4/TO/PHB) was used to stably transfect the $\mathrm{LNCaP} / \mathrm{Luc}$ cells to produce a new stable cell line, LNCaP/Luc/PHBcDNA. Additionally, a doxycycline-inducible RNAi hairpin vector ( $\mathrm{p} 2 \mathrm{TetR} / \mathrm{PHB})$, based on previously validated RNAi oligos (Gamble et al. 2004), was used to generate an inducible PHB knockdown cell line LNCaP/Luc/PHB-RNAi, allowing effects of manipulating PHB levels to be studied within a chromatinized system both in vitro and in vivo.

Treating LNCaP/Luc/PHB-cDNA cells with increasing doses of doxycycline resulted in a dosedependent increase in PHB protein and cDNA levels (Fig. 2A). Conversely, treating LNCaP/Luc/PHBRNAi cells with doxycycline resulted in a decrease in PHB protein and cDNA levels (Fig. 2B). To assess the effects of PHB upon AR activity, hormonally starved LNCaP/Luc/PHB-cDNA and LNCaP/Luc/ PHB-RNAi cells were treated with increasing concentrations of androgen (MB), in the presence of two different doses of doxycycline (to give submaximal and maximal effects on PHB levels respectively), for $24 \mathrm{~h}$. Doxycycline-induced PHB overexpression significantly reduced the activity of the luciferase reporter in a dose-dependent manner (Fig. 2C), while doxycycline-induced PHB knockdown increased the activity of the luciferase reporter in a dose-dependent manner (Fig. 2D). The effects of modulating PHB levels on expression of the endogenous androgenregulated gene, PSA, were also studied. Maximal PHB overexpression resulted in a large reduction in PSA expression at all MB concentrations, as measured by real-time PCR (Fig. 2E). Conversely, PHB knockdown resulted in increased androgen-regulated PSA expression (Fig. 2F).

The effects of PHB manipulation on androgendependent cell growth in culture were studied by FACS analysis of doxycycline-treated cells. In full serum, PHB overexpression $(+$ dox $)$ resulted in accumulation at $G_{1} / S$ and a subsequent reduction in percentage of cells in S-phase (Fig. 2G), i.e. PHB increase prevented cell cycle entry. Hormonally starved cells showed no significant effects, but when treated with androgen, PHB overexpression again reduced the percentage of cells in S-phase. This was most evident at $10 \mathrm{nM}$ MB when cells are growing most rapidly. RNAi knockdown of PHB did not significantly affect the cell cycle distribution of cells growing in full serum, presumably since cell growth was maximal (Fig. 2H). In hormonally starved cells, a slightly increased cell number was seen in S-phase (4\% increasing to $6 \%$ ) upon PHB knockdown. However, when hormonally starved cells were induced to re-enter the cell cycle by androgen treatment at $1 \mathrm{nM} \mathrm{MB}$, the amount of cells entering S-phase doubled with doxycycline-induced PHB knockdown. Hence, reduction in PHB levels led to an increase in androgen-dependent growth of prostate cancer cells. This effect was no longer evident when cells were treated with $10 \mathrm{nM}$ MB presumably since, as in the case of full serum, cells were already growing at the maximum rate under these conditions.

\section{PHB inhibits androgen-mediated growth of prostate cancer cells in vivo}

Castrated male nude mice bearing $\mathrm{LNCaP} / \mathrm{Luc}$ xenografts were used to study the effects of testosterone treatment on tumour growth and AR activity. Mice were given daily injections of testosterone propionate until tumours were confirmed 2 weeks after challenge, at which time tumours were given a relative tumour volume (RTV) of 1 . Tumours were grown to an RTV of $1.5\left(\sim 200 \mathrm{~mm}^{3}\right)$, and mice were then separated into treatment groups with or without testosterone and doxycycline. Mice given androgen supplementation had average serum testosterone levels of $2.7 \mathrm{ng} / \mathrm{ml}$, 
A
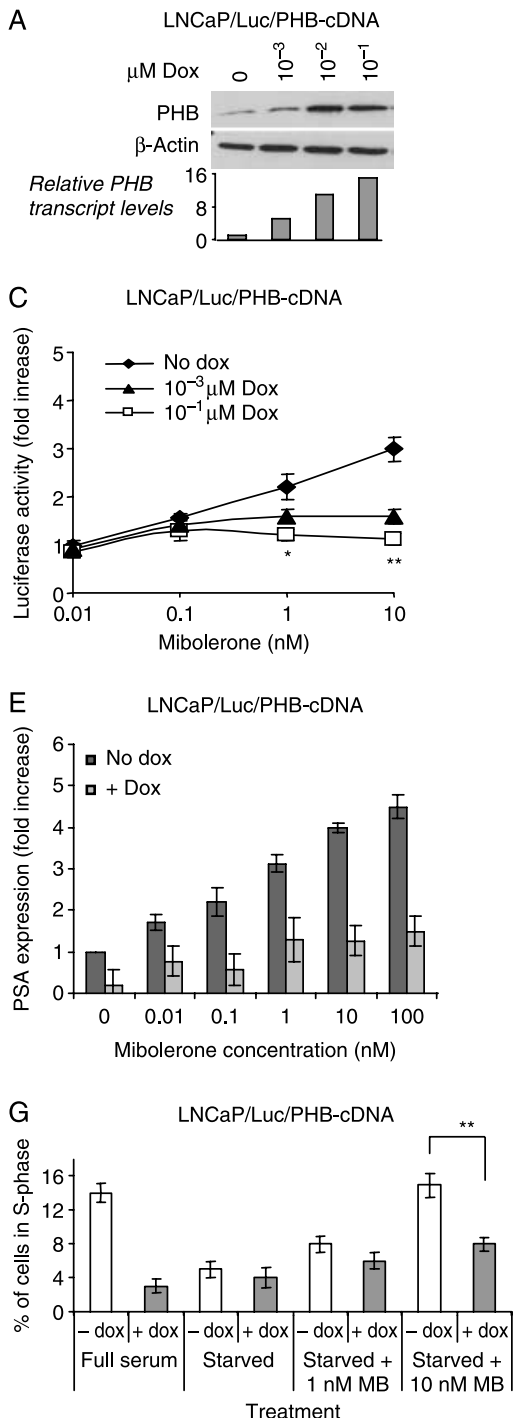

B
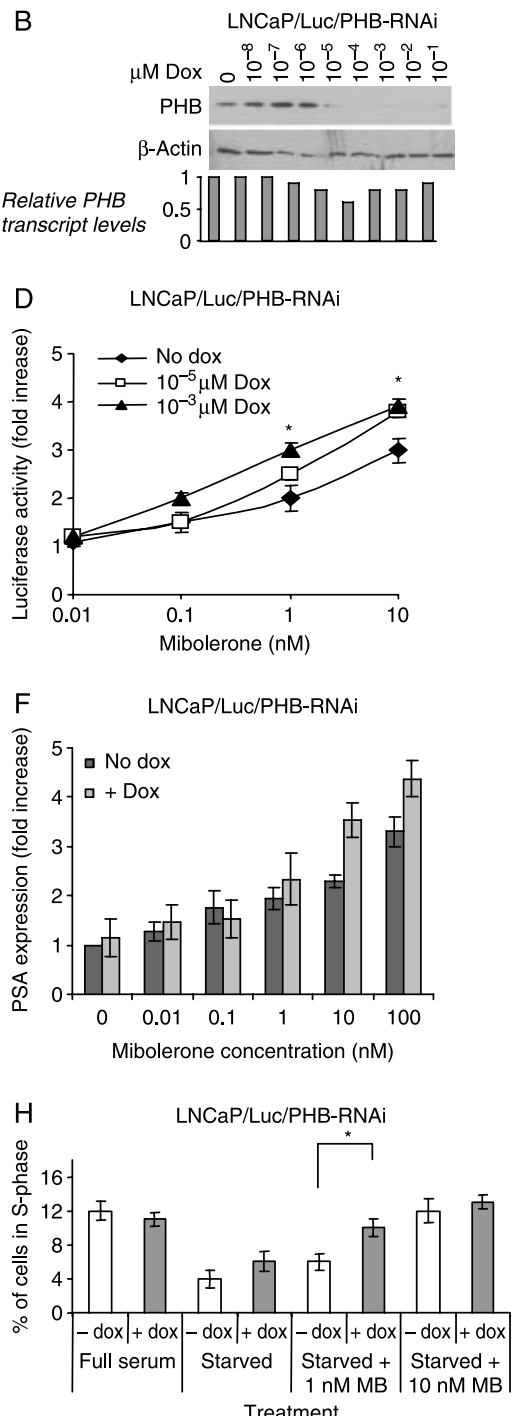

Figure 2 Analysis of stable cell lines with altered PHB levels. (A and B) Western blot analysis of PHB levels in PHB-overexpressing (A) and PHB-knockdown (B) cells treated with increasing doses of doxycycline for $24 \mathrm{~h}$. Relative PHB cDNA values from RT-qPCR, normalized to GAPDH, are included. (C and D) Luciferase activity from LNCaP/Luc/PHB-cDNA (C) and LNCaP/Luc/PHB-RNAi (D) cells treated with $\mathrm{MB}(0-10 \mathrm{nM})$ and increasing doxycycline levels. (E and F) Taqman RT-PCR analysis of PSA levels from starved LNCaP/Luc/PHB-cDNA (E) and LNCaP/Luc/PHB-RNAi (F) cells treated with increasing concentrations of MB with or without doxycycline at 1 or $0.001 \mu \mathrm{M}$ respectively. Mean \pm S.E.M. from three experiments is shown. ( $\mathrm{G}$ and $\mathrm{H}$ ) S-phase distributions of LNCaP/Luc/PHB-cDNA (G) and LNCaP/Luc/PHB-RNAi $(\mathrm{H})$ cells determined by FACS analysis. Cells were grown either in medium with full serum or starvation medium $\pm \mathrm{MB}$ as indicated. ${ }^{\star \star} P<0.01,{ }^{\star} P<0.05$ ( $t$-test analysis).

slightly below the normal physiological range seen for humans (3-10 $\mathrm{ng} / \mathrm{ml})$, while the vehicle control group showed testosterone levels of $<0.1 \mathrm{ng} / \mathrm{ml}$. In testosterone-treated mice, tumours grew with a mean doubling time of 15 days, until the average RTV reached 3 $\left(\sim 450 \mathrm{~mm}^{3}\right)$. However, in the vehicle control group, tumour growth ceased upon testosterone withdrawal, followed by statistically significant tumour shrinkage within 48 h (Fig. 3A), with a terminal average RTV of 0.74 after 36 days.
Androgen-induced luciferase activity within these tumours was analysed by light emission from live animals, imaged after i.p. injection of D-luciferin. Tumours in testosterone-treated mice showed average light emission of 420 photons/s per $\mathrm{mm}^{3}$ of tumour, whereas the tumours from vehicle-treated mice showed a gradual drop in light emissions with a final activity ranging from undetectable to 200 photons/s per $\mathrm{mm}^{3}$ (Fig. 3B and C). Histological examination and cell proliferation counts were obtained from these two 

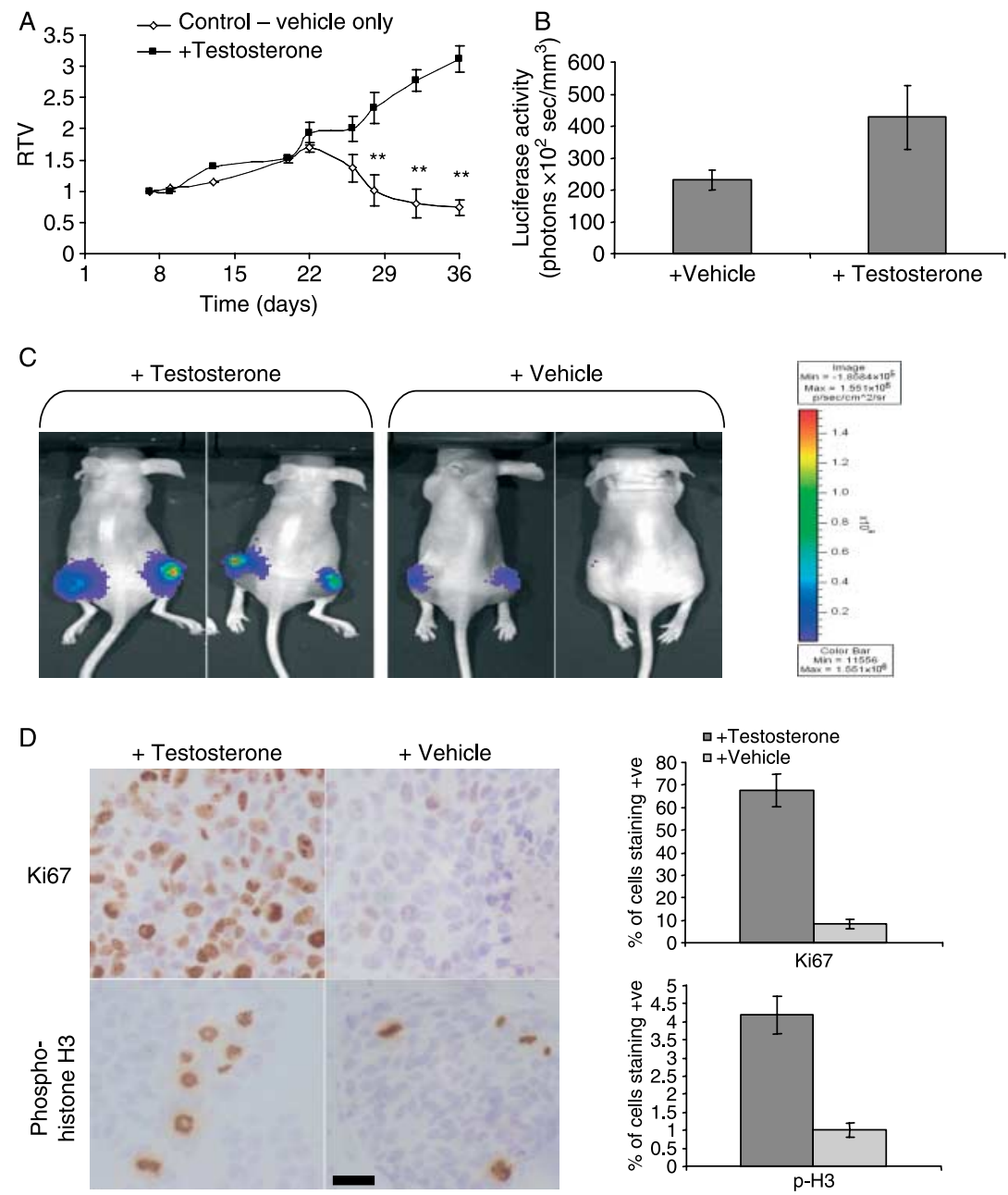

Figure 3 Effect of testosterone withdrawal on growth of LNCaP/Luc tumour xenografts in nude mice. (A) Relative tumour volume (RTV) of LNCaP/Luc tumours over 36 days. Each point represents the mean \pm s.E.M. of six to eight observations. Treatment groups assigned on day 20. ${ }^{* *} P<0.01,{ }^{*} P<0.05$ (Mann-Whitney analysis). (B) Light emission from LNCaP/Luc tumours normalized to tumour volume $\left(\mathrm{mm}^{3}\right)$ at day 36. (C) Bioluminescent imaging of luciferase activity in testosterone-treated and vehicle-treated mice harbouring LNCaP/Luc tumours at day 36, following injection with D-luciferin. (D) Immunohistochemical staining of Ki67 (upper panel) and phospho-Histone H3 (lower panel) from sections of LNCaP/Luc tumour xenografts from mice treated with testosterone or vehicle. Scale bar, $25 \mu \mathrm{m}$. Counting results from five separate tumours is shown on the right.

groups. Testosterone withdrawal produced significant effects on cellular proliferation, with tumours showing rapid reduction in cells staining positive for the proliferation marker Ki67 and the mitosis marker phospho-histone H3 (Fig. 3D), demonstrating the testosterone requirement of the $\mathrm{LNCaP} / \mathrm{Luc}$ tumours.

Next, the same parameters were investigated in mice bearing LNCaP/Luc/PHB-cDNA tumours. Serum doxycycline measurements from mice indicated that optimal serum concentrations for overexpression and knockdown respectively were obtained by adding $200 \mathrm{mg} / \mathrm{ml}$ in drinking water for LNCaP/Luc/PHB-cDNA xenografts and $20 \mathrm{mg} / \mathrm{ml}$ for LNCaP/Luc/PHB-RNAi xenografts (data not shown). In testosterone-treated mice, doxycycline treatment resulted in a statistically significant reduction in RTV as compared with untreated controls, indicating that PHB overexpression repressed androgen-mediated growth in vivo (Fig. 4A). In the absence of testosterone, doxycycline-treated mice showed no tumour growth, but interestingly did not exhibit tumour shrinkage as was seen for the no doxycycline control (Fig. 4C).

Mice bearing LNCaP/Luc/PHB-RNAi tumours, plus testosterone, which were given doxycycline, showed a statistically significant increase in RTV as compared with no doxycycline controls (Fig. 4B), indicating that reduction in PHB levels promoted androgen-dependent tumour growth in vivo. Without testosterone, tumours 
A $\quad$ LNCaP/Luc/PHB-cDNA + testosterone

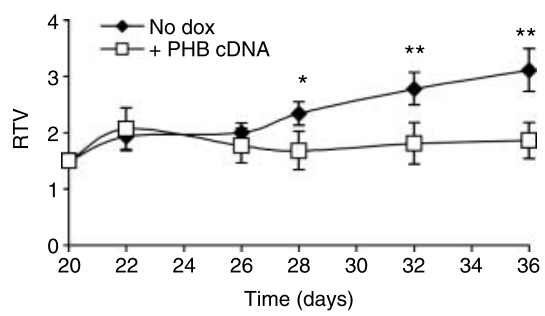

C LNCaP/Luc/PHB-cDNA + vehicle
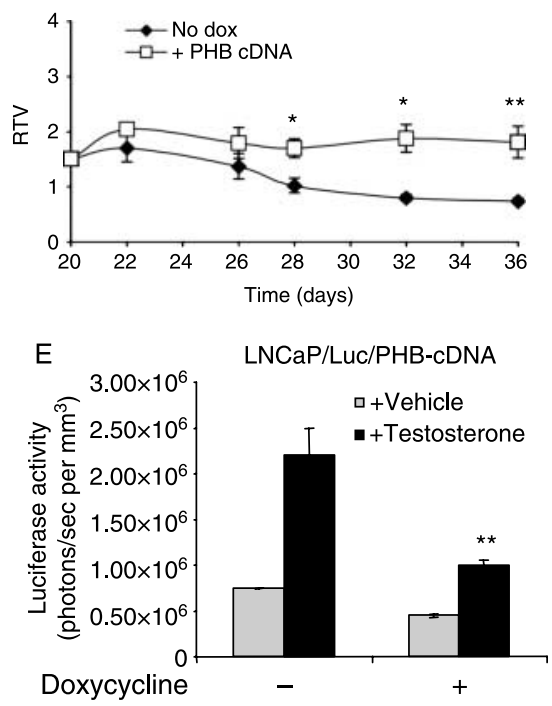

B LNCaP/Luc/PHB-RNAi + testosterone

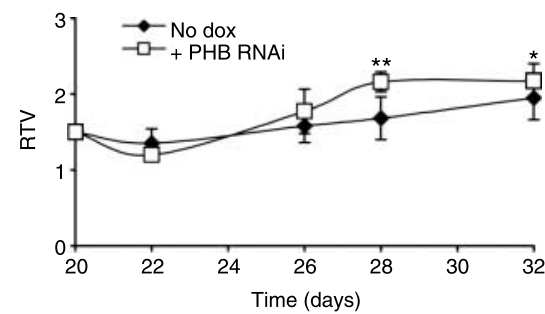

D LNCaP/Luc/PHB-RNAi + vehicle

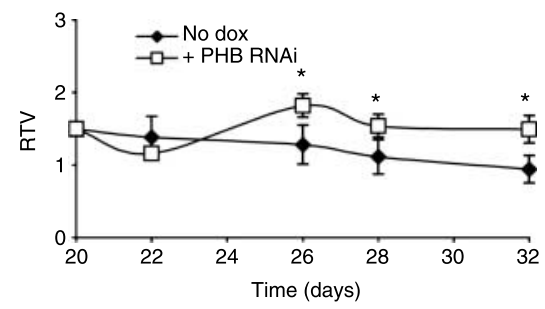

F LNCaP/Luc/PHB-RNAi

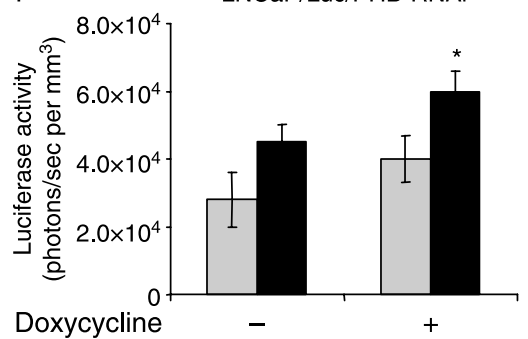

Figure 4 Effects of manipulating PHB levels on tumour growth and AR activity in vivo. (A-D) Relative tumour volumes of LNCaP/Luc xenografts with increased ( $A$ and $C$ ) or decreased (B and D) PHB levels in castrated nude male mice treated with (A and $B)$ or without $(\mathrm{C}$ and $\mathrm{D})$ testosterone. Each point represents mean \pm S.E.M. of six to eight tumours. ${ }^{\star \star} P<0.01,{ }^{\star} P<0.05$ (Mann-Whitney analysis). $(\mathrm{E}$ and $\mathrm{F}$ ) Bioluminescent imaging results from LNCaP/Luc/PHB-cDNA (E) and LNCaP/Luc/PHB-RNAi (F) tumours at day 36. ${ }^{\star *} P<0.01,{ }^{\star} P<0.05$ ( $t$-test).

in mice given doxycycline also showed a brief increase in growth, but tumour RTVs dropped gradually thereafter, although significantly greater than in the no doxycycline control animals (Fig. 4D). Hence, a reduction in PHB levels was only partially able to mimic androgen treatment in promoting cell growth.

\section{PHB represses AR activity in vivo}

Light emission measurements from mice carrying LNCaP/Luc/PHB-cDNA tumours indicated that PHB overexpression also resulted in a significant reduction in androgen-mediated luciferase activity within these tumours (Fig. 4E), with $60 \%$ less light emission. PHB overexpression had no significant effect in the absence of testosterone. Conversely, reduction in PHB by RNAi resulted in a 30\% increase in androgen-mediated luciferase activity within the tumours in the testosterone-treated group (Fig. 4F). Interestingly, PHB knockdown also increased the activity of the $A R$ in the absence of hormone for up to 24-48 h after doxycycline treatment; however, this was not maintained in the absence of testosterone.

\section{PHB affects cell proliferation in LNCaP/Luc tumours}

The doxycycline induction of PHB overexpression and knockdown could clearly be seen within the tumours by immunohistochemistry (Fig. 5A). Cell proliferation counts were obtained from these two cell lines. Testosterone withdrawal produced significant effects on cellular proliferation in both cell lines, with a rapid reduction in cells staining positive for the proliferation marker phospho-histone $\mathrm{H} 3$ (Fig. 5B and C). PHB overexpression inhibited the testosterone-induced cellular proliferation, as indicated by reduction in histone H3 staining (Fig. 5B). However, PHB knockdown resulted in a higher level of cellular proliferation in the tumours, in the presence and absence of testosterone (Fig. 5C). 

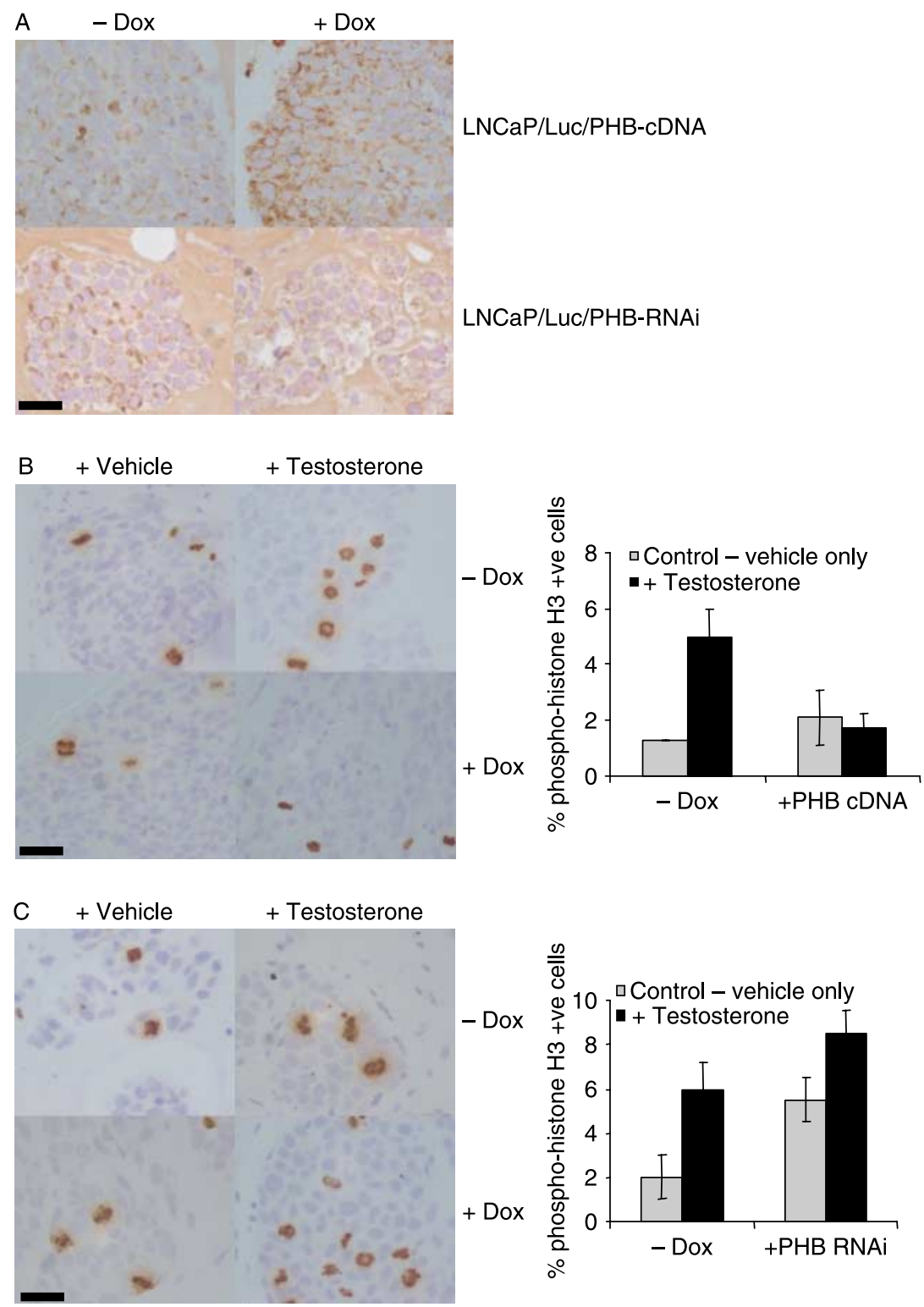

Figure 5 Immunohistochemistry analysis of formalin-fixed tumour sections. (A) PHB staining of LNCaP/Luc/PHB-cDNA (upper panel) and LNCaP/Luc/PHB-RNAi (lower panel) from mice \pm doxycycline. (B and C) Phospho-histone $\mathrm{H} 3$ staining of LNCaP/Luc/PHB-cDNA (B) and LNCaP/Luc/PHB-RNAi (C) tumours from mice treated \pm testosterone and \pm doxycycline. Phospho-histone H3-positive cell counts from five separate tumours are shown on the right. Scale bar, $25 \mu \mathrm{m}$.

\section{Discussion}

We set out to study AR activity within a prostate tumour xenograft model and to examine the role of a potential corepressor protein, $\mathrm{PHB}$, in modulating this activity in a real time in vivo setting. To this end, a doxycycline-inducible system for manipulating PHB protein levels was generated in LNCaP cells expressing an androgen-responsive reporter. LNCaP cells were used as they exhibit androgen-regulated growth and gene expression, and form xenografts in nude mice. In humans, prostate cancer is initially androgen dependent, but progresses to a hormonerefractory or androgen-independent stage. The AR remains active within the majority of these hormonerefractory tumours and is required for prostate cell growth, differentiation and gene expression. The mechanisms of $\mathrm{AR}$ activation within such tumours are poorly understood. AR mutations and/or amplification are frequently found in advanced tumours, and it has been postulated that decreases in corepressor 
proteins or increases in coactivator proteins could also be potential activation pathways for the progression of tumours to this androgen-independent stage (Isaacs \& Isaacs 2004).

PHB is a cell cycle-regulatory protein, involved in repressing E2F-mediated gene expression, and has been reported to repress the $\mathrm{AR}$ in vitro. Overexpression of PHB in LNCaP cells inhibited androgen-mediated cell cycle entry, cell growth and gene expression, both in cell culture and in tumour xenografts. However, some subtle differences were seen in the effects of PHB in tumour xenografts. For example, hormone starvation of $\mathrm{LNCaP}$ cells in culture leads to cell cycle arrest in $G_{0} / G_{1}$, whereas in xenografts, androgen withdrawal leads to rapid tumour shrinkage and involution with significant apoptosis and/or necrosis. Indeed, a significant number of cells stained positive with the TUNEL assay in these androgen-deprived tumours (Supplementary data). Upon doxycycline-induced PHB overexpression, tumour growth was inhibited even in the presence of androgen. However, in the absence of androgen, tumours with PHB overexpression showed an apparent inhibition of tumour involution and apoptosis, suggesting that PHB overexpression leads to cell cycle arrest regardless of hormone effects, and may consequently have a protective role against apoptosis caused by hormonal starvation stress. Similar protective effects have been shown for PHB when $\mathrm{LNCaP}$ cells were deprived of growth factors (Vander Heiden et al. 2002) or treated with cytotoxic agents such as camptothecin (Fusaro et al. 2002, Rastogi et al. 2006).

Reduction of PHB levels in LNCaP/Luc cells increased androgen-stimulated entry into S-phase, AR activation as measured by the luciferase assay and increased growth. In vivo, reduction in PHB levels resulted in an initial increase in tumour size, regardless of androgen treatment. However, this increase in tumour size was only maintained in the presence of androgen. Some tumour shrinkage or involution was seen, but no changes in apoptotic staining were apparent (Supplementary Figure 3, which can be viewed online at http://erc.endocrinology-journals. org/supplemental/). These data suggest that PHB has a potent effect in the cell, not only repressing $A R$ signalling but also repressing genes involved in apoptosis and inhibiting cell cycle entry. Additionally, the reduction in PHB protein may be sufficient to activate cell cycle and growth pathways within the cell, avoiding or circumventing hormone starvationinduced apoptosis.
PHB has a role in recruiting HDACs and chromatin remodelling complexes to DNA, causing chromatin condensation and presumably inhibiting the DNA binding of transcription factors such as AR. Removal of PHB via RNAi may result in decreased chromatin condensation, making DNA more accessible for transcription factor binding. The roles of PHB and the AR may also overlap in their control of cell cycle entry. The AR may play a part in DNA replication initiation and licensing in certain cell types (Litvinov et al. 2006), and PHB inhibits key proteins in the $\mathrm{G}_{1}-\mathrm{S}$ transition, namely pRb and E2F (Wang et al. 1999a,b, Balk \& Knudsen 2008). It is likely that indirect interactions or competition between $\mathrm{AR}$ and PHB would arise at this $\mathrm{G}_{1} / \mathrm{S}$ boundary. Direct interaction between AR and PHB remains elusive (Gamble et al. 2004), but recent evidence for a more direct interaction between PHB and steroid receptors exists. PHB associates with oestrogen-regulated promoters directly in the absence of hormone, supporting its role as a transcriptional corepressor (He et al. 2008), and may physically interfere with transcription factor binding to the response element.

From this study, PHB overexpression inhibits cell growth, but may also protect against hormonal starvation during anti-androgen therapy. Conversely, a reduction in PHB levels may increase the ability of the AR to promote cell growth and gene expression, but could cause inappropriate cell cycle entry and mitochondrial dysfunction. PHB is an upregulated marker for distinguishing benign hyperplasia from prostate cancer (Ummanni et al. 2008), but any extensive studies on the levels of PHB protein within prostate cancers and its effects on disease progression are currently lacking. However, recent studies in breast cancer indicate that the simple protein level measurement was insufficient, as high PHB levels masked underlying inactivating mutations in the $\mathrm{Rb}$ and $\mathrm{E} 2 \mathrm{~F}-$ binding regions of PHB (Sato et al. 1992, 1993). PHB has been shown to be downregulated in gliomas (Chumbalkar et al. 2005). Loss of the PHB repressor protein may impact on the repressive effectiveness of hormone antagonists such as the partial anti-oestrogen tamoxifen (Wang et al. 2004) and androgen antagonists (Dai et al. 2008), indicating that PHB may have different tumour supporting roles at different times in the development of hormone-dependent cancer. Additionally, the growth-stimulating properties of knocking down PHB in the absence of testosterone, as seen in this study, may be due to increased activity of $\mathrm{AR}$ in a low testosterone environment or indeed a lack of repressive activity in the presence of adrenal androgens, some of which e.g. androstenedione have 
partial antagonist effects e.g. androstenedione (Chen et al. 2004). Certainly, the current data suggest further studies will be needed before pharmacologically increasing corepressor protein levels, or activity could be used as a therapeutic strategy for hormonedependent cancers. However, in support of this concept, recently, a potential mechanism for in vivo reduction in PHB levels has been suggested by Liu et al. They reported that PHB is a potential target of the microRNA-27a, which is upregulated in gastric adenocarcinoma and may act as an oncogene by reducing PHB levels (Liu et al. 2009).

Finally, there are many potential corepressors and coactivators of AR within prostate cells, any of which either alone or in combination may have powerful effects upon AR signalling and hence tumour progression. We have generated a model in which the effects of these cofactors upon AR signalling can be studied within prostate tumour xenografts simultaneously with tumour growth. As proof of principle, modulating just one of these potential corepressors resulted in profound changes to androgen activity and tumour growth. The generated LNCaP/Luc model has potential as a new tool to evaluate disease progression, the role of AR and PHB in this process, and to test new therapies for prostate cancer treatment.

\section{Declaration of interest}

The authors declare that there is no conflict of interest that could be perceived as prejudicing the impartiality of the research reported.

\section{Funding}

This work was supported by grants from the Association of International Cancer Research, the Medical Research Council and the Hammersmith Hospital Special Trustees.

\section{Acknowledgements}

We thank Mrs Julia Alete and Dr Florine Morrison for their technical advice and assistance, Dr Georges Vassaux for advice and plasmids, and Dr Tahereh Kamelati for critical reading of the manuscript.

\section{References}

Agoulnik IU \& Weigel NL 2006 Androgen receptor action in hormone-dependent and recurrent prostate cancer. Journal of Cellular Biochemistry 99 362-372.

Balk SP \& Knudsen KE 2008 AR, the cell cycle, and prostate cancer. Nuclear Receptor Signaling 6 e001.
Beato M, Chalepakis G, Schauer M \& Slater EP 1989 DNA regulatory elements for steroid hormones. Journal of Steroid Biochemistry 32 737-747.

Brinkmann AO \& Trapman J 2000 Prostate cancer schemes for androgen escape. Nature Medicine 6 628-629.

Chen F, Knecht K, Leu C, Rutledge SJ, Scafonas A, Gambone C, Vogel R, Zhang H, Kasparcova V, Bai C et al. 2004 Partial agonist/antagonist properties of androstenedione and 4-androsten-3beta,17beta-diol. Journal of Steroid Biochemistry and Molecular Biology 91 247-257.

Choi D, Lee SJ, Hong S, Kim IH \& Kang S 2008 Prohibitin interacts with RNF2 and regulates E2F1 function via dual pathways. Oncogene 27 1716-1725.

Chumbalkar VC, Subhashini C, Dhople VM, Sundaram CS, Jagannadham MV, Kumar KN, Srinivas PN, Mythili R, Rao MK, Kulkarni MJ et al. 2005 Differential protein expression in human gliomas and molecular insights. Proteomics 5 1167-1177.

Claessens F, Alen P, Devos A, Peeters B, Verhoeven G \& Rombauts W 1996 The androgen-specific probasin response element 2 interacts differentially with androgen and glucocorticoid receptors. Journal of Biological Chemistry 271 19013-19016.

Coates PJ, Jamieson DJ, Smart K, Prescott AR \& Hall PA 1997 The prohibitin family of mitochondrial proteins regulate replicative lifespan. Current Biology 7 607-610.

Dai Y, Ngo D, Jacob J, Forman LW \& Faller DV 2008 Prohibitin and the SWI/SNF ATPase subunit BRG1 are required for effective androgen antagonist-mediated transcriptional repression of androgen receptor-regulated genes. Carcinogenesis 29 1725-1733.

Dodd JG, Sheppard PC \& Matusik RJ 1983 Characterization and cloning of rat dorsal prostate mRNAs. Androgen regulation of two closely related abundant mRNAs. Journal of Biological Chemistry 258 10731-10737.

Ferlay J, Autier P, Boniol M, Heanue M, Colombet M \& Boyle P 2007 Estimates of the cancer incidence and mortality in Europe in 2006. Annals of Oncology 18 581-592.

Fusaro G, Wang S \& Chellappan S 2002 Differential regulation of $\mathrm{Rb}$ family proteins and prohibitin during camptothecin-induced apoptosis. Oncogene 21 4539-4548.

Gamble SC, Odontiadis M, Waxman J, Westbrook JA, Dunn MJ, Wait R, Lam EW \& Bevan CL 2004 Androgens target prohibitin to regulate proliferation of prostate cancer cells. Oncogene 23 2996-3004.

Gamble SC, Chotai D, Odontiadis M, Dart DA, Brooke GN, Powell SM, Reebye V, Varela-Carver A, Kawano Y, Waxman J et al. 2007 Prohibitin, a protein downregulated by androgens, represses androgen receptor activity. Oncogene 26 1757-1768.

Gelmann EP 2002 Molecular biology of the androgen receptor. Journal of Clinical Oncology 20 3001-3015.

He B, Feng Q, Mukherjee A, Lonard DM, DeMayo FJ, Katzenellenbogen BS, Lydon JP \& O’Malley BW 2008 A repressive role for prohibitin in estrogen signaling. Molecular Endocrinology 22 344-360. 
Vander Heiden MG, Choy JS, VanderWeele DJ, Brace JL, Harris MH, Bauer DE, Prange B, Kron SJ, Thompson CB \& Rudin CM 2002 Bcl-x(L) complements Saccharomyces cerevisiae genes that facilitate the switch from glycolytic to oxidative metabolism. Journal of Biological Chemistry 277 44870-44876.

Isaacs JT \& Isaacs WB 2004 Androgen receptor outwits prostate cancer drugs. Nature Medicine 10 26-27.

Janik P, Briand P \& Hartmann NR 1975 The effect of estrone-progesterone treatment on cell proliferation kinetics of hormone-dependent GR mouse mammary tumors. Cancer Research 35 3698-3704.

Jemal A, Thun MJ, Ward EE, Henley SJ, Cokkinides VE \& Murray TE 2008 Mortality from leading causes by education and race in the United States, 2001. American Journal of Preventive Medicine 34 1-8.

Kokontis JM \& Liao S 1999 Molecular action of androgen in the normal and neoplastic prostate. Vitamins and Hormones 55 219-307.

Litvinov IV, Vander Griend DJ, Antony L, Dalrymple S, De Marzo AM, Drake CG \& Isaacs JT 2006 Androgen receptor as a licensing factor for DNA replication in androgen-sensitive prostate cancer cells. PNAS $\mathbf{1 0 3}$ 15085-15090.

Liu T, Tang H, Lang Y, Liu M \& Li X 2009 MicroRNA-27a functions as an oncogene in gastric adenocarcinoma by targeting prohibitin. Cancer Letters 273 233-242.

McClung JK, Jupe ER, Liu XT \& Dell'Orco RT 1995 Prohibitin: potential role in senescence, development, and tumor suppression. Experimental Gerontology 30 99-124.

Mostov KE 1994 Transepithelial transport of immunoglobulins. Annual Review of Immunology 12 63-84.

Nijtmans LG, Artal SM, Grivell LA \& Coates PJ 2002 The mitochondrial PHB complex: roles in mitochondrial respiratory complex assembly, ageing and degenerative disease. Cellular and Molecular Life Sciences 59 143-155.

Powell SM, Christiaens V, Voulgaraki D, Waxman J, Claessens F \& Bevan CL 2004 Mechanisms of androgen receptor signalling via steroid receptor coactivator-1 in prostate. Endocrine-Related Cancer 11 117-130.

Powell SM, Brooke GN, Whitaker HC, Reebye V, Gamble SC, Chotai D, Dart DA, Belandia B \& Bevan CL 2006 Mechanisms of androgen receptor repression in prostate cancer. Biochemical Society Transactions 34 1124-1127.

Rastogi S, Joshi B, Fusaro G \& Chellappan S 2006 Camptothecin induces nuclear export of prohibitin preferentially in transformed cells through a CRM-1dependent mechanism. Journal of Biological Chemistry 281 2951-2959.

Rennie PS, Bruchovsky N, Leco KJ, Sheppard PC, McQueen SA, Cheng H, Snoek R, Hamel A, Bock ME, MacDonald BS et al. 1993 Characterization of two cis-acting DNA elements involved in the androgen regulation of the probasin gene. Molecular Endocrinology 7 23-36.
Sato T, Saito H, Swensen J, Olifant A, Wood C, Danner D, Sakamoto T, Takita K, Kasumi F, Miki Y et al. 1992 The human prohibitin gene located on chromosome $17 \mathrm{q} 21$ is mutated in sporadic breast cancer. Cancer Research 52 1643-1646.

Sato T, Sakamoto T, Takita K, Saito H, Okui K \& Nakamura Y 1993 The human prohibitin (PHB) gene family and its somatic mutations in human tumors. Genomics $\mathbf{1 7}$ 762-764.

Schoenmakers E, Alen P, Verrijdt G, Peeters B, Verhoeven G, Rombauts W \& Claessens F 1999 Differential DNA binding by the androgen and glucocorticoid receptors involves the second $\mathrm{Zn}$-finger and a C-terminal extension of the DNA-binding domains. Biochemical Journal 341 515-521.

Schoenmakers E, Verrijdt G, Peeters B, Verhoeven G, Rombauts W \& Claessens F 2000 Differences in DNA binding characteristics of the androgen and glucocorticoid receptors can determine hormone-specific responses. Journal of Biological Chemistry 275 12290-12297.

Skehan P, Storeng R, Scudiero D, Monks A, McMahon J, Vistica D, Warren JT, Bokesch H, Kenney S \& Boyd MR 1990 New colorimetric cytotoxicity assay for anticancerdrug screening. Journal of the National Cancer Institute 82 1107-1112.

Tsai MJ \& O'Malley BW 1994 Molecular mechanisms of action of steroid/thyroid receptor superfamily members. Annual Review of Biochemistry 63 451-486.

Ummanni R, Junker H, Zimmermann U, Venz S, Teller S, Giebel J, Scharf C, Woenckhaus C, Dombrowski F \& Walther R 2008 Prohibitin identified by proteomic analysis of prostate biopsies distinguishes hyperplasia and cancer. Cancer Letters 266 171-185.

Verrijdt G, Schoenmakers E, Alen P, Haelens A, Peeters B, Rombauts W \& Claessens F 1999 Androgen specificity of a response unit upstream of the human secretory component gene is mediated by differential receptor binding to an essential androgen response element. Molecular Endocrinology 13 1558-1570.

Wang S, Nath N, Adlam M \& Chellappan S 1999a Prohibitin, a potential tumor suppressor, interacts with RB and regulates E2F function. Oncogene 18 3501-3510.

Wang S, Nath N, Fusaro G \& Chellappan S 1999b Rb and prohibitin target distinct regions of E2F1 for repression and respond to different upstream signals. Molecular and Cellular Biology 19 7447-7460.

Wang S, Zhang B \& Faller DV 2004 BRG1/BRM, and prohibitin are required for growth suppression by estrogen antagonists. EMBO Journal 23 2293-2303.

Wang L, Hsu CL \& Chang C 2005 Androgen receptor corepressors: an overview. Prostate 63 117-130.

Zhang L, Johnson M, Le KH, Sato M, Ilagan R, Iyer M, Gambhir SS, Wu L \& Carey M 2003 Interrogating androgen receptor function in recurrent prostate cancer. Cancer Research 63 4552-4560. 